\title{
A vanished humeral head mimicking Gorham's disease in a patient with Diabetes Mellitus
}

\section{Retraction Note}

The article entitled A vanished humeral head mimicking Gorham's disease in a patient with Diabetes Mellitus" has been accepted for publication in the Clinical Practice (Therapy): Open Access considering the statements provided in the article as personal opinion of the author which was found not having any conflict or biasness towards anything. As the article was a perspective one, information provided by the author was considered as an opinion to be expressed through publication. Publisher took decision to make the article online solely based on the reviewers suggestion which considered the article not but a personal opinion of the author. However, it is found that the author have some personal concerns and issues, therefore, being retracted from the journal.

Haider M Al Attia*

Department of Internal Medicine and Rheumatology, Al Noor Hospital, Airport Road, PO Box 60420, Abu Dhabi, United Arab Emirates

*Author for correspondence: 